\title{
BMJ Open Ecological study of playground space and physical activity among primary school children
}

\author{
Anne C Grunseit (D) ,1,2 Blythe Jane O'Hara (D) ," Bradley Drayton, ${ }^{1}$ \\ Vincent Learnihan, ${ }^{3}$ Louise L Hardy (D) , ${ }^{1}$ Eve Clark, ${ }^{4}$ Paul Klarenaar, ${ }^{4}$ Lina Engelen ${ }^{1}$
}

To cite: Grunseit AC, O'Hara BJ, Drayton B, et al. Ecological study of playground space and physical activity among primary school children. BMJ Open 2020;10:e034586. doi:10.1136/ bmjopen-2019-034586

- Prepublication history and additional material for this paper are available online. To view these files, please visit the journal online (http://dx.doi. org/10.1136/bmjopen-2019034586).

Received 28 September 2019 Revised 30 April 2020 Accepted 29 May 2020

Check for updates

(c) Author(s) (or their employer(s)) 2020. Re-use permitted under CC BY-NC. No commercial re-use. See rights and permissions. Published by BMJ.

${ }^{1}$ Prevention Research Collaboration, Sydney School of Public Health, University of Sydney, Camperdown, New South Wales, Australia

${ }^{2}$ The Australian Prevention Partnership Centre, Sydney, New South Wales, Australia

${ }^{3}$ Centre for Research and Action in Public Health, Faculty of Health, University of Canberra, Canberra, Australian Capital Territory, Australia

${ }^{4}$ Northern Sydney Local Health District Health Promotion, Brookvale, New South Wales, Australia

Correspondence to

Dr Anne C Grunseit;

anne.grunseit@sydney.edu.au

\section{ABSTRACT}

Objectives To examine the relationship between school playground size and total physical activity (PA), fitness and fundamental movement skills (FMS) of primary school students.

Design Cross-sectional ecological analysis.

Setting 43 primary schools in New South Wales, Australia. Participants Data were from 5238 students, aged 5 to 12 years, participating in the Schools Physical Activity and Nutrition Survey.

Outcome measures Self (for age $\geq 11$ years) and parent (for age $<11$ years) report of PA (meeting PA recommendations and number of days meeting recommendations), objectively measured FMS and cardiorespiratory and muscular fitness.

Results Associations between playground space and measures of PA and fitness were mostly non-linear and moderated by loose equipment. Students in schools with no loose equipment showed a weak association between space and meeting PA recommendations (selfreport). In schools with equipment, students' predicted probability of meeting PA recommendations increased sharply between $15 \mathrm{~m}^{2}$ and $25 \mathrm{~m}^{2}$ per student from 0.04 (95\% Cl: 0.01 to 0.08 ) to 0.30 (95\% Cl: 0.14 to 0.46 ), but at $30 \mathrm{~m}^{2}$ returned to levels comparable to students in schools with no equipment $(0.18,95 \% \mathrm{Cl}: 0.07$ to 0.28). For cardiorespiratory fitness, in schools with no loose equipment, probabilities for being in the healthy cardiovascular fitness zone varied between 0.66 and 0.77 , showing no consistent trend. Students in schools with loose equipment had a predicted probability of being in the healthy fitness zone of 0.56 ( $95 \% \mathrm{Cl}: 0.41$ to 0.71 ) at $15 \mathrm{~m}^{2}$ per student, which rose to $0.75(95 \% \mathrm{Cl}: 0.63$ to 0.86 ) at $20 \mathrm{~m}^{2}$ per student. There was no relationship between space and FMS.

Conclusions School space guidelines need to incorporate sufficient playground space for students. Our study provides evidence supporting better PA outcomes with increasing space up to $25 \mathrm{~m}^{2}$ per student, and access to loose equipment, however further research is required to determine precise thresholds for minimum space. Intersectoral planning and cooperation is required to meet the needs of growing school populations.

\section{INTRODUCTION}

Physical activity (PA) is important for the health and well-being of children and young people, yet only a minority meet daily

\section{Strengths and limitations of this study}

A strength of this study is inclusion of measures of physical activity (PA) as well fitness and fundamental movement skills.

- The survey sample was large, randomly sampled and representative of the New South Wales (NSW) primary school children population which allows the findings to be generalised across NSW schools and students.

- A further strength of the study was that a substantial range of school playground sizes were included and that the analysis took into account moderating effects of loose play equipment.

- A limitation of the study is that whilst the PA instrument is valid, it is limited by self-report and cannot distinguish where the PA took place at school or outside of school hours. The data were also cross-sectional.

- Assumptions about the availability of playground space from the Geographical Information Systems data were made and were not able to be further validated; therefore space may be underestimated as not all non-building, non-car park areas were included.

recommended levels. ${ }^{1}$ Strategies to improve children's PA are needed and previous research suggests that the school environment has a major impact on children's PA levels. Research on the effect of school playground size also suggests a positive relationship with children's PA. One Spanish accelerometry study of primary school children showed children in larger play areas (ie, $>15 \mathrm{~m}^{2}$ per child) were more active than those in smaller play areas (ie, $<8 \mathrm{~m}^{2}$ per child $)^{2}$ as did another study from Greece on 12-year-old children's self-report PA levels. ${ }^{3}$ Research conducted in the UK among primary school aged children also found that as play-space-perchild increases (decreased density), so does vigorous activity, and sedentary behaviour decreases. ${ }^{4}$ Other Australian research noted similar associations, but found that the effect 
of density varied across gender and physical competence, favouring boys (over girls) and boys with higher motor skills over boys with lower skills. ${ }^{5}$ Intervention research confirms these correlational studies, finding that strategies which reduce playground density in primary schools are effective at increasing PA levels, ${ }^{6}$ particularly among less active children. ${ }^{7}$ Moreover, these quantitative findings are consistent with children's own qualitative perceptions that lack of access to, and unsuitability of, playground space is a barrier to their engagement in PA. ${ }^{89}$

While the evidence described above shows the incremental relationship between playground space and the amount and type of PA occurring in school, the relationship with total PA (including meeting recommendations) is less certain. Some authors suggest that PA undertaken at school may replace PA undertaken elsewhere, or vice versa (the 'activitystat ' hypothesis) $;{ }^{11}$ other studies have found no compensatory relationship. ${ }^{12} 13$ One UK study examined PA across different segments of the school day in 10 to 11-year-olds and found an incremental effect of playground area on vigorous but not moderate PA in school time and no relationship with either in outof-school time. ${ }^{14}$ The question therefore remains as to whether children are more active overall and have superior indicators of physical competence and fitness the larger and/or the lower the density of the play space at their school. Further, there is consistent evidence that playground features such as fixed and loose play equipment can influence children's $\mathrm{PA}^{6}$ but whether they modify the effect of available playground space on PA is yet to be examined.

In Australia, the school population in the state of $\mathrm{New}$ South Wales (NSW) is expected to grow by $14.4 \%$ between 2016 and $2026^{15}$ fuelling concerns that playground spaces may be lost to new classrooms. ${ }^{16}{ }^{17}$ One Victorian study showed $55.2 \%$ of primary schools surveyed had lost playground area to new classrooms in recent years. ${ }^{18}$ Yet no guidelines exist for schools on the appropriate or necessary amount of outdoor space required to facilitate students' PA. 'Free play space' (ie, playground space) is defined as the space remaining on a school site after the footprint of permanent and demountable buildings, car parks, footpaths and buffer areas have been deducted from the total space. ${ }^{16}$ In NSW the current space guidelines state that $10 \mathrm{~m}^{2}$ per student is preferred for schools with enrolments of 1000 students; $^{19}$ US playground guidelines require a minimum of 75 square feet ${ }^{2}\left(7 \mathrm{~m}^{2}\right)$ per student. ${ }^{20}$ However, the playground space requirements in these and other guidelines ${ }^{21} 22$ are grounded in concerns for safety rather than encouraging healthenhancing PA.

The aim of this study was to examine the relationship between school playground areas and students' total PA. Specifically, (1) the relationship between playground space per student and their PA, cardiorespiratory fitness and fundamental movement skills, (2) whether these associations are modified by playground equipment and (3) whether any 'thresholds' emerge to indicate a minimum amount of playground area required for students to meet health-enhancing PA.

\section{METHODS \\ Design}

Our study was an ecological analysis of the relationship between primary school playground space and students' PA. We used data from a population health survey of school children conducted between February and March $2015^{23}$ and playground space data derived from Geographical Information Systems (GIS) to estimate the playground space in schools which participated in the survey.

\section{Sampling and data collection}

The sampling frame comprised all NSW schools except special education schools (eg, special needs, elite sport) and small schools $(<180$ enrolments). Schools were randomly sampled from each education sector (Government, Independent, Catholic) proportional to enrolment, then classes randomly selected and students in those classes invited to participate using a random number generator. This study includes only primary school children (ages 5 to 12 years; $n=5238$ ) from 43 schools. Data were collected in each school by trained field teams.

\section{Child information}

Parents of children in kindergarten, grades 2 and 4 (age $<11$ years) completed a questionnaire at the time of consent and children in grade 6 (age $\geq 11$ years) completed the same questionnaire at school. Sociodemographic information included the child's sex, date of birth, language spoken most often at home and residential postcode. Children were categorised as living in urban or rural areas from their postcode using the Australian Statistical Geography Standard. ${ }^{24}$ Language at home was categorised into English, Middle Eastern, Asian and European speaking backgrounds. ${ }^{25}$ Children's anthropometry included height $(\mathrm{cm})$, weight $(\mathrm{kg})$ and waist circumference $(\mathrm{cm})$ measured using standard instruments and procedures to the nearest $0.1 \mathrm{~cm}, 0.1 \mathrm{~kg}$ and $0.1 \mathrm{~cm}$, respectively. Bodymass index z-scores $(\mathrm{BMIz})^{26}$ and waist-to-height ratios $^{27}$ were calculated according to established procedures. Total sedentary time on a week day outside of school was assessed using the Adolescent Sedentary Activity Questionnaire ${ }^{28}$ and active travel to school (minutes per day) was averaged over the five school days. ${ }^{23}$

\section{School-level data}

Principals from participating schools completed a questionnaire on the schools' physical environment, policies and practices to promote PA including questions on space and equipment in and around the school (eg, fields, playground markings, bike paths around school) and their availability at recess and lunch. The Index of Community Socio-Educational Advantage (ICSEA) was used as 
a measure of the school's student population socioeconomic status relative to other schools. ${ }^{29}$

\section{No patient and public involvement}

This study was done without participant involvement. Participants were not: invited to comment on the study design; consulted in relation to outcome measures; involved in interpreting the results; and were not invited to contribute to the writing or editing of this paper.

\section{Measures}

Outcome measures

Total PA was based on a validated single-item measure of moderate-to-vigorous physical activity (MVPA) ${ }^{30}$ Respondents were asked, 'Over the past 7 days, on how many days were you/your child engaged in MVPA for at least $60 \mathrm{~min}$ (this can be accumulated over the entire day, for example, in bouts of $10 \mathrm{~min}$ ) each day?' Responses ranged from 'No days' to '7 days' and was operationalised as: (1) a count of number of days and (2) whether the child met the PA guidelines $(7=$ meets guideline and $<7=$ did not meet guideline).

Seven fundamental movement skills (FMS) were assessed; four locomotor skills (sprint run, vertical jump, side gallop and leap) and three object control skills (catch, overarm throw and kick) using process-oriented checklists for each skill. ${ }^{31}$ The number of components ( $n=6$ per skill) correctly demonstrated by each student was recorded. Cardiorespiratory fitness (CRF) was assessed by the 20 metre shuttle run test, a valid and reliable test of CRF in children. ${ }^{32} 33$ Students were categorised as 'needs improvement' or in the 'healthy fitness zone' (HFZ) according to the age-and-sex adjusted criterion-reference standard from FitnessGram. ${ }^{34}$ Muscular strength was assessed by the standing broad jump, a reliable field test of muscular strength in youth. ${ }^{35}$ Students were categorised as 'needs improvement' or in the HFZ according to the age-sex adjusted $40^{\text {th }}$ centile of the distance jumped normative values for Australian children's standing broad jump. ${ }^{36}$

Table 1 Physical activity data collected by grade level

\begin{tabular}{|c|c|c|c|c|}
\hline \multirow[b]{2}{*}{ Outcome } & \multicolumn{4}{|l|}{ Grade level } \\
\hline & Kindergarten & 2 & 4 & 6 \\
\hline $\begin{array}{l}\text { Fundamental movement } \\
\text { skills }\end{array}$ & & $x$ & $x$ & $x$ \\
\hline
\end{tabular}

Days per week meeting PA recommendation (60 mins moderate to vigorous activity)

\begin{tabular}{llll}
\multicolumn{1}{c}{ Parent report } & $X$ & $X$ & \\
\multicolumn{1}{c}{ Self-report } & & & $X$ \\
$\begin{array}{l}20 \text { metre shuttle run test } \\
\text { (CRF) }\end{array}$ & & $X$ & $X$ \\
$\begin{array}{l}\text { Standing broad jump } \\
\text { (muscular strength) }\end{array}$ & $X$ & $X$ & $X$ \\
\hline
\end{tabular}

CRF, cardiorespiratory fitness; PA, physical activity.
Table 1 shows the outcome measures available for grade level as not all age groups were measured on all outcomes.

\section{Exposure measure}

All participating primary school locations were geocoded to the street address level. Playground space was defined as any area of the school site that could feasibly be used for outdoor recreation by students during recess/lunch breaks as defined by the NSW State Government (as stated above). ${ }^{16}$ Aerial photography (including Google Street View), building footprints ${ }^{37}$ and land parcel data defining school boundaries ${ }^{38}$ allowed play space polygons to be digitised using GIS software. ${ }^{39}$ Playground space area was measured in square metres and excluded areas of buildings, car parks, driveways and other built structures from the total school site area. Where identifiable, playground space which was covered (eg, by a shade structure) was also included. Most commonly, playground space included marked and unmarked courts, grassed areas and sporting fields.

\section{Covariates}

Categorical covariates (reference category) selected a priori for inclusion in the analysis were: sex (boys), residence (urban), language spoken most at home (English), waist-to-height ratio $(<0.5)$; continuous variables were age (years), BMIz, active travel on school days (minutes) and average daily sedentary time (minutes). At the school level, we included availability and use of loose play equipment (reference category: no loose equipment) and fixed play equipment as these have been associated with $\mathrm{PA}^{49} 40$ and ICSEA (continuous). Population density (measured in thousands per square kilometre for the Statistical Area Level 2 the school was located within ${ }^{41}$ was included as it has consistently shown a positive relationship with PA (particularly walking). ${ }^{42}$

\section{Data analysis}

Continuous variables (age, active school travel, sedentary time, population density, BMIz and ICSEA) were centred at their mean values. Active school travel and sedentary time were also truncated at maximum plausible values ( $\leq 120$ and $620 \mathrm{~min}$, respectively), and scaled by their SD. Each covariate was graphed against playground space (not shown), to determine whether there were sufficient data to make reliable comparisons between the levels of the covariate. Presence of fixed equipment and utilisation of equipment during recess and lunch (ie, if equipment was available, it was used) varied little and therefore were excluded. Two schools were outliers in terms of space, and space per student $\left(>100 \mathrm{~m}^{2}\right.$ per student $)$ and exerted undue influence in preliminary analyses and were therefore excluded from subsequent modelling.

\section{Model fitting}

We fitted four models per outcome comprising the possible combinations of (1) type of association of the outcome with free play space (linear/non-linear) and (2) 
inclusion of an interaction of free play space and loose play equipment. Non-linear associations were modelled using restricted cubic splines with five knots. Knot placement was determined by percentiles (across the entire available sample) ${ }^{43}$ The final model for each outcome was non-linear if the estimated coefficients corresponding to non-linear parts of restricted cubic spline, jointly tested, were significantly different from zero. Interaction terms were included in the final model if, jointly tested, they were significantly different from zero. The threshold for statistical significance was set at $\mathrm{p}=0.05$. The FMS outcomes were modelled using linear regression, meeting PA recommendations using generalised linear models using binomial distribution and a log link, days meeting PA recommendations using poisson regression, cardiorespiratory and muscular fitness using logistic regression. Meeting PA recommendations derived from parental (grades kindergarten,2 and 4) and (grade 6) self-report were analysed separately because of the different data sources.

\section{Reporting}

Due to the difficulty in interpreting spline models in a meaningful way, ${ }^{44}$ the results for the (adjusted) relationship between the playground space and each outcome are presented as graphs and marginal means across the range of playground space in our data. Marginal means for models including a loose play equipment by playground space interaction term are estimated separately for schools with and without loose play equipment. If a model with no interaction was selected, margins were predicted at the estimated prevalence of students having access to loose play equipment. All other covariates are held constant at the following values: age, active school travel time, sedentary time, population density and ICSEA at zero; sex (boys), waist-to-height ratio $(<0.5)$; language background (English); residence (urban).

All analyses were conducted in Stata/IC V.15.1 (College Station, Texas, USA), with checking and corroboration in $\mathrm{R}^{45}$ using the survey package V.3.35. ${ }^{46}$ In Stata, the 'svy' suit of commands were used to account for complex sampling, post stratification and analysis of subpopulations (using the 'subpop' command to ensure correct weighting).

\section{RESULTS}

The demographic characteristics of the weighted sample of primary school children $(n=5238)$ across the covariates and the grade levels are shown in table 2. The sample was fairly evenly split between boys and girls and $86 \%$ were from English-speaking backgrounds. Just over threequarters of the sample fell within the healthy weight range and only a minority had waist-to-height ratios which exceeded 0.5 . On average, students spent only $5 \mathrm{~min}$ in active travel to school and over 4 hours in sedentary time outside of school hours. Approximately one-third of the schools had loose equipment available for student use and their ICSEA scores were close to the national average of 1000 . The average amount of playground space per child was $38 \mathrm{~m}^{2}$ (range $1.37 \mathrm{~m}^{2}$ to $289.1 \mathrm{~m}^{2}$, median $=38.2 \mathrm{~m}^{2}$ ).

The results for the regression analyses of PA against playground space adjusted for the covariates are shown in figure 1. Across the eight outcomes, there were mostly non-linear associations between playground space and measures of students' PA, and large sections of the spaceper-student range had weak or no association. However, for several outcomes, we observed a sharp increase in predicted mean of the outcome (ie, greater PA) from $15 \mathrm{~m}^{2}$ to $20 / 25 \mathrm{~m}^{2}$ per student and then a decline or levelling out. Several outcomes exhibited different associations with free play space per student depending on whether loose play equipment was present or not; schools with equipment tended to have more strongly non-linear associations between space and the outcomes. Further detail over each of the outcomes is given below.

\section{Fundamental movement skills}

The final models for locomotor and object control FMS were linear models with no loose play equipment by space interaction. For both, our data showed no association between FMS and playground space (panels A and B).

\section{Meeting physical activity recommendations}

For parental report of PA, the association between meeting the PA recommendations and playground space was non-linear and modified by the availability of loose play equipment. In schools without loose equipment, there was a small but significant increased probability of meeting PA recommendations as playground space increased (panel C). In schools with loose equipment, the trend was generally flatter, with the exception of a limited increase in the probability meeting PA guidelines at about $25 \mathrm{~m}^{2}$ per student. In terms of number of days achieving 60 min MVPA (panel D), we found no evidence of effect modification by loose play equipment. The association with playground space was non-linear with little change up to approximately $40 \mathrm{~m}^{2}$ per student and then the probability of meeting recommendations steadily increased up to the maximum value of $83 \mathrm{~m}^{2}$ per student.

For self-report PA, generally the probability of meeting PA recommendations and number of days achieving 60 min MVPA was lower than for parent-report data (panels E and F). Among schools with no loose equipment, the association with meeting recommendations was weak, declining slightly as space increased. In schools with equipment, the predicted probability of meeting PA recommendations increased sharply between $15 \mathrm{~m}^{2}$ and $25 \mathrm{~m}^{2}$ per student to 0.30 (95\% CI: 0.14 to 0.46 ), dropped back to 0.18 (95\% CI: 0.07 to 0.28 ) at $30 \mathrm{~m}^{2}$ and then increased steadily (online supplementary table $\mathrm{S} 1$ ). However, the wide CIs reflect greater uncertainty in the estimations due to the smaller number of schools in this subgroup. For the predicted number of days achieving 60 min MVPA by students attending schools without loose equipment, the association with space declines slightly 


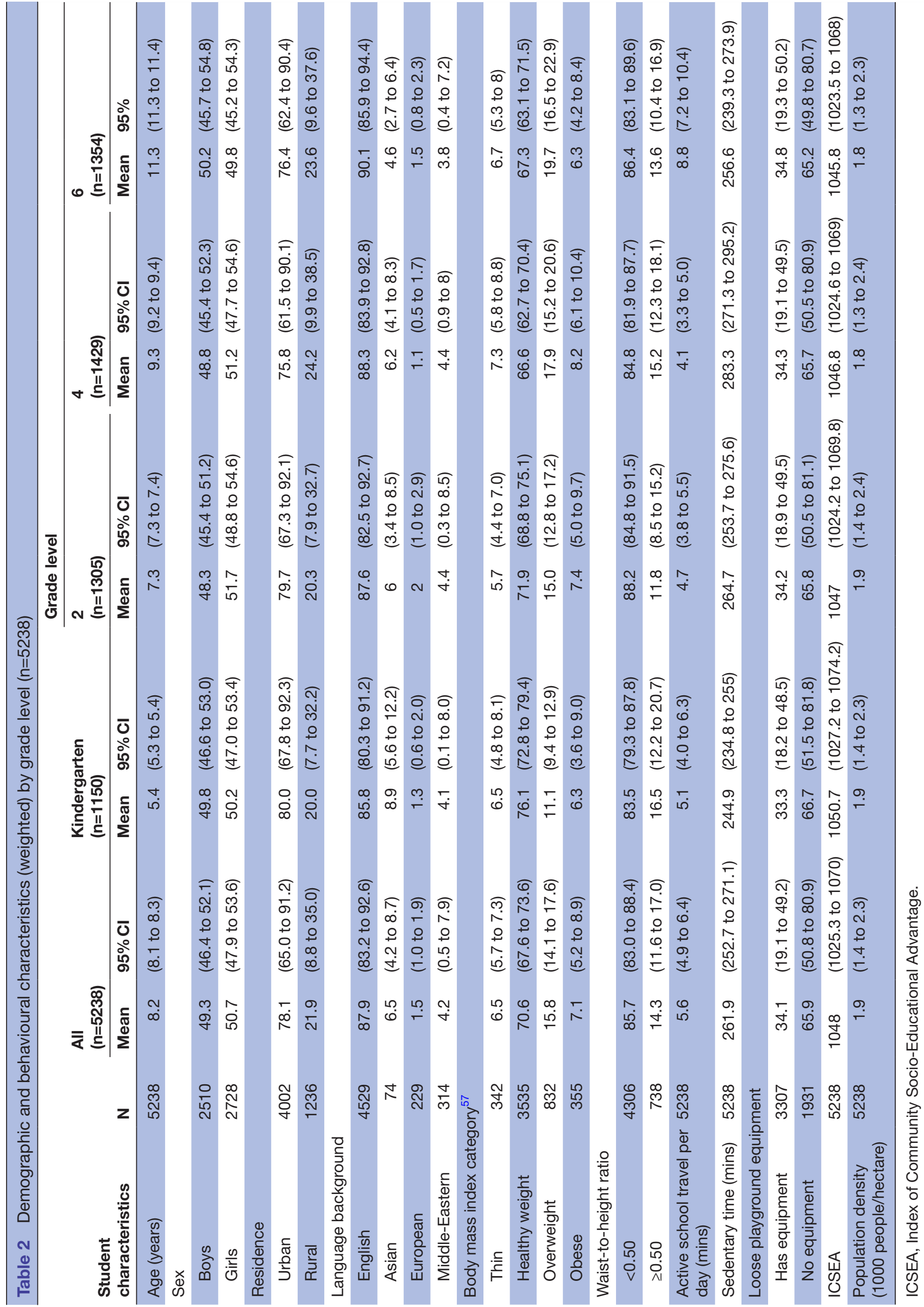




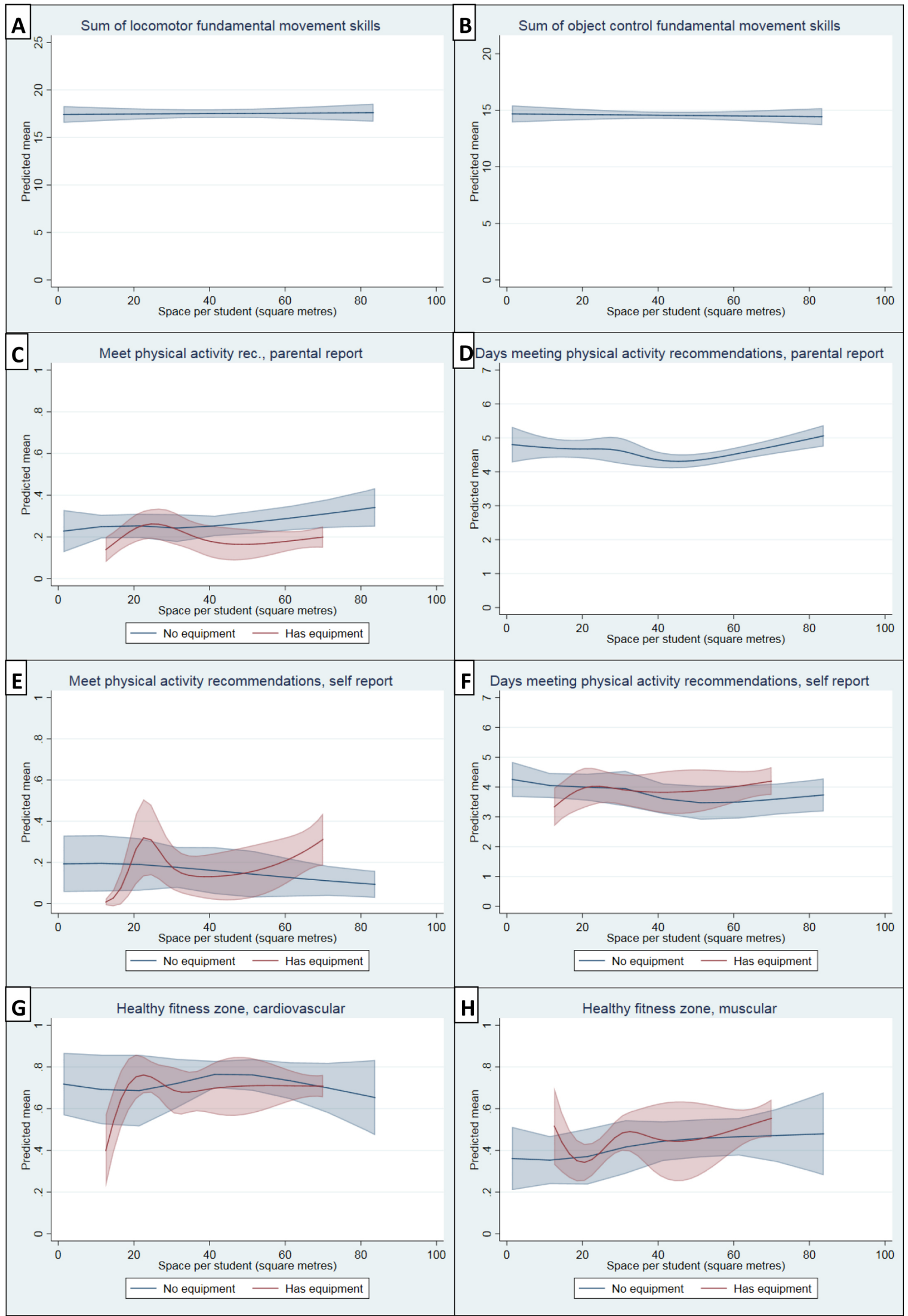

Figure 1 Predicted marginal means estimated from our final models. Marginal means are predicted across the range of space per student observed in our data. Covariates are held at constant levels: All continuous variables (age, total sedentary time, active travel time, BMIz and ICSEA) were centred and held at 0 (their mean) for prediction. Predictions were for boys with waistto-height ratio $<0.5$, English-speaking language background and urban locality. BMIz, body mass index z-score; ICSEA, Index of Community Socio-Educational Advantage; rec., recommendations. 
over playground space, but in equipped schools, a sharp increase from 3.6 (95\% CI: 3.0 to 4.2 ) to 4 days (95\% CI: 3.5 to 4.6 ) between $15 \mathrm{~m}^{2}$ and $25 \mathrm{~m}^{2}$ per student, respectively, flattening out across larger play spaces.

\section{Cardiorespiratory fitness}

There was a non-linear relationship between CRF and playground space, modified by loose play equipment. In schools with no equipment, probabilities varied between 0.66 and 0.77 , peaking in the 40 to $65 \mathrm{~m}^{2}$ range but showing no consistent trend (panel G). In schools with equipment, there is a sharp increase in the predicted probability of a student being in the HFZ in schools in the lower third of space-per-child: the predicted probability of being in the healthy cardiovascular fitness zone is 0.56 (95\% CI: 0.42 to 0.71$)$ at $15 \mathrm{~m}^{2}$ per student and rises to 0.75 (95\% CI: 0.63 to 0.86 ) at $20 \mathrm{~m}^{2}$ per student. From this point to the maximum space in our sample, there was a weak to no association.

\section{Muscular strength}

For muscular strength, the association with playground space was non-linear and modified by loose play equipment (panel $\mathrm{H})$. There is a modest but increasing trend towards higher muscular strength with increasing space among schools with no loose play equipment. For schools with equipment, the predicted mean probability of being in the healthy muscular fitness zone drops sharply between 15 to $20 \mathrm{~m}^{2}$ per child from 0.42 (95\% CI: 0.29 to 0.56 ) to 0.34 (95\% CI: 0.25 to 0.43 ), before increasing back to 0.48 (95\% CI: 0.40 to 0.56$)$ at $30 \mathrm{~m}^{2}$ and variable trajectory thereafter, perhaps in part due to the underlying small sample (online supplementary table S1).

\section{Other covariates}

Where covariates had significant effects, they were mostly in the expected direction. Briefly, BMIz and waist-to-height ratio were inversely related to PA outcomes (although not for all or for the same outcomes) as was sedentary time. Girls, Asian and/or Middle Eastern students had lower PA than boys and English-speaking background students, respectively. School socioeconomic status and active travel time were positively associated with some PA outcomes. Unexpectedly, population density was negatively associated with parent (meeting recommendations and days meeting recommendations) and child (days meeting recommendations) report PA.

\section{DISCUSSION}

To our knowledge, this is one of the few ecological studies to examine the relationship between school playground space and primary school children's PA, and the first using a large sample and objective measures of FMS and physical fitness. While previous research has demonstrated that children are more active in playground spaces which are larger, ${ }^{2}$ only one study has examined the impact on total activity taking into account individual demographic characteristics and school level factors. ${ }^{14}$ That study, conducted in the UK, used accelerometry and stratified analyses by school and non-school segments of the day and concluded that despite the significant relationship between playground size and PA, the effect sizes were too small to have practical application. Yet, the range of playground space was narrow (2.8 to $7.6 \mathrm{~m}^{2} /$ student) and the analysis did not take into account loose play equipment. The current study covered a wide range of school playground sizes ( 1.4 to $83.8 \mathrm{~m}^{2} /$ student included in analyses) and modelled non-linear effects and moderation by loose equipment, allowing expansion of the implications over a wider range of school contexts. While complex, our results suggest that setting standards for school playground space and local area planning of schools needs to take into account the impact of space on children's PA, as well as safety. Our findings are discussed in greater detail below in the context of previous research and implications for practice.

The combined effect of loose equipment and playground space in this study was not linear and showed having loose equipment had a positive and rapidly incremental effect on outcomes as the space increased up to $25 \mathrm{~m}^{2}$ per student. For example, below $20 \mathrm{~m}^{2}$ the probability of a student $(<11$ years) meeting PA recommendations in a school with loose equipment (vs no loose equipment) is 0.17 (vs 0.25 ), 0.04 (vs 0.19 ) for a student aged 11 and 12 years and 0.56 (vs 0.69 ) for a student of any age to be in the healthy range for cardiorespiratory fitness (online supplementary table $\mathrm{S} 1$ ). At $25 \mathrm{~m}^{2}$ the corresponding values are notably higher at $0.26,0.30$ and 0.75 with the probabilities unchanged for students in schools with no loose equipment. We observed variation between the parental report data and child selfreport data. Specifically, having loose equipment in the former conferred a benefit only in the 20 to $30 \mathrm{~m}^{2}$ per child range and bringing the children's PA to levels equivalent to children in schools with no loose equipment. By contrast, with the older children, sufficient PA not only showed increases in the 20 to $25 \mathrm{~m}^{2}$ per child schools in the presence of loose play equipment, but maintained an advantage in the 45 to $65 \mathrm{~m}^{2}$ per child schools. The confounding of reporting mechanism (self-report versus parent) and age group in these data hinders a clear interpretation of these findings; based on the estimates alone it may be that having loose equipment may be more important for older children, whereas for younger children the amount of space per child may be the priority.

The finding that loose equipment influences PA is consistent with findings in previous research ${ }^{694}$ and points to at least one way in which smaller schools might enhance the effect of what space they have available. Loose equipment has been found to increase PA through providing opportunities for children to manipulate their play environment. However, one intervention study by Engelen $e t a t^{40}$ which found increased objectively measured PA for children in schools where a loose equipment intervention was implemented in comparison to the control schools, did not find change was associated with available playground space per child. ${ }^{40}$ Notably, in that study, the amount of playground 
space varied from $0.9 \mathrm{~m}^{2}$ to $11 \mathrm{~m}^{2}$ per child, well short of the area identified in the current study as showing a positive effect for PA. Therefore, the influence of the amount of playground space in combination with loose equipment may only be evident above certain space thresholds.

Despite the positive relationship with self-reported and parent-reported total PA, we did not find an association between the amount of playground space available and two measures of FMS. Given the strong predictive association between levels of PA and FMS competence ${ }^{47}$ and the positive association between playground space and our other two objective measures of fitness, the reason for these outcomes is unclear. A previous study showed that the impacts of sedentary behaviour on FMS were not apparent until children reached high school age (ie, 12/13 years of age) $;^{48}$ therefore it may also be that the impact of playground space on children's FMS are delayed because the effect is cumulative. Further research examining the relationship using longitudinal data is warranted to track the proximal and distal outcomes of playground size.

More broadly, our findings may suggest that there are important inflexion points for minimum playground space as it relates to PA which could be incorporated into guidelines and trigger the invocation of alternatives should a school not meet a space threshold. Many schools are in areas which would not allow for expansion, and therefore policies must include alternative strategies to mitigate the effect of small playground space. For example, schools could implement staggered lunch times or gain access to nearby space. When redeveloping, adding new buildings or placing demountable classrooms, ensuring minimal impact on playground space could be addressed through vertical school design which is already gaining traction in inner city areas. ${ }^{49}$ While many schools already use these strategies, guidelines and specifications for school design which maximise students' opportunities for PA as well as for safety need to be developed and grounded in evidence.

While our covariates mostly showed results in the expected direction, our finding of an inverse relationship between population density and three of four PA measures runs counter to previous studies showing a positive effect. For students $<11$ years, we observed an average $16 \%$ reduction in the probability of meeting PA recommendations per increase of 1000 persons per square kilometre. Previous research shows population density is positively related with active travel to and from school through closer commuting distances and presence of walking infrastructure ${ }^{50}$ Our study adjusted for both active travel to school and the amount of playground space (as inner urban areas are more likely to have smaller spaces but higher population density) and a negative relationship with total PA emerged. While the mechanism for this result is unclear, with greater density, children's PA opportunities outside of travelling to school are limited because of higher traffic volumes and speeds ${ }^{5152}$ and less green space per capita ${ }^{53}{ }^{54}$ underscoring the importance of contextualising PA opportunities at school in those of the local environment.
A strength of this study is inclusion of measures of PA as well their sequelae, namely fitness and FMS. The analysis was retrospective and therefore the measurement could not influence measures. The analyses were adjusted for a large number of factors known to influence PA outcomes and covered a wide range of playground space/child. The survey sample was large, randomly sampled and representative of the NSW primary school children population which allows the findings to be generalised across NSW schools and students. Limitations include, the cross-sectional study design which limits the capacity to draw definitive conclusions about causality in the associations observed. Further, while the question for PA is valid, it is limited by self-report and cannot distinguish whether the PA took place at school or outside of school hours. However, as stated in the introduction, our study focussed on total PA and the primary objective of health promotion advocates is that children are sufficiently active irrespective of where PA is accumulated. Further, all else being equal (and assuming we have corrected for relevant confounding) there is no compelling evidence that PA inside and outside of school are interdependent. Assumptions about the availability of playground space from the GIS data were made and were not able to be further validated; therefore space may be underestimated as not all non-building and non-car park areas were included. Further, the data were sparse in certain ranges of playground space, especially when stratified by the presence/ absence of loose equipment. Working with official school plans in future studies may be one approach to improving play space classification. The steep incline observed in several models is derived from data from many students, but just a few schools. Further work should extend measurement beyond our endpoints, and with more schools to build on the trends observed here.

\section{CONCLUSION}

Given that low activity in school is compensated by less than half of children beyond the school setting ${ }^{14}$ and opportunities within the school day, such as physical education and recess, can make important contributions to children's overall $\mathrm{PA}^{55}$ it is important that conditions which promote health enhancing PA at school are maximised. School space guidelines should be grounded in evidence regarding the impact of playground space and design on the PA of students while at school and in total. To this end, future research could clarify the thresholds implied by the current analysis using longitudinal methods, natural experiments and intervention studies. Schools with limited capacity to redesign or retrofit greater space should be assisted in identifying feasible alternative spaces and/or arrangements such as sharing facilities and flexible timetabling. Further, a comprehensive approach is required, intersecting health promoting schools with urban design and planning. Governments at all levels need to balance the goals of providing living environments that promote PA through increased density with town planning and school 
design that ensures schools have sufficient playground space for current and future student populations. ${ }^{56}$

Acknowledgements The authors would like to thank the schools, students and their parents for participating in the survey and Arlita Willman for her comments on the final draft. The authors would also like to acknowledge the funding provided by the NSW Ministry of Health in respect of the population health survey of school children.

Contributors ACG designed the study, contributed to the analysis design and interpretation of the results, drafted the introduction and edited the manuscript. BJO contributed to the analysis design, and drafted the introduction and edited later drafts. BD conducted the analysis and drafted the results. VL derived measures from GIS data and contributed to the design of the analysis, drafted relevant parts of the methods and commented on later drafts. PK and EC conceived the study, contributed to the study design and provided input on the interpretation and implications of the findings, and critical review of the manuscript. LLH is the principle investigator on SPANS and contributed to the planning of the analysis and critical review of the manuscript. LE contributed to the study design and analysis, contributed to early drafts and provided critical review of the manuscript.

Funding Funding by Northern Sydney Local Health District was provided for this study.

\section{Competing interests None declared.}

Patient consent for publication Not required.

Ethics approval Ethics approvals were granted by The University of Sydney (№: 2018/048), the NSW Department of Education and Training and the NSW Catholic Education Commission. Informed written consent by students and their carers was required for participation.

Provenance and peer review Not commissioned; externally peer reviewed. Data availability statement № data are available.

Open access This is an open access article distributed in accordance with the Creative Commons Attribution Non Commercial (CC BY-NC 4.0) license, which permits others to distribute, remix, adapt, build upon this work non-commercially, and license their derivative works on different terms, provided the original work is properly cited, appropriate credit is given, any changes made indicated, and the use is non-commercial. See: http://creativecommons.org/licenses/by-nc/4.0/.

\section{ORCID IDs}

Anne C Grunseit http://orcid.org/0000-0003-1250-3265

Blythe Jane 0'Hara http://orcid.org/0000-0001-9984-0656

Louise L Hardy http://orcid.org/0000-0001-8656-6758

\section{REFERENCES}

1 Tremblay MS, Gray CE, Akinroye K, et al. Physical activity of children: a global matrix of grades comparing 15 countries. J Phys Act Health 2014;11 Suppl 1:S113-25.

2 Escalante Y, Backx K, Saavedra J M, et al. Play area and physical activity in recess in primary schools. Kinesiol Int J Fundam Appl Kinesiol 2012;44:123-9.

3 Delidou E, Matsouka O, Nikolaidis C. Influence of school playground size and equipment on the physical activity of students during recess. Eur Phy Educ Rev 2016;22:215-24.

4 Ridgers ND, Fairclough SJ, Stratton G. Variables associated with children's physical activity levels during recess: the A-class project. Int J Behav Nutr Phys Act 2010;7:74.

5 Harten N, Olds T, Dollman J. The effects of gender, motor skills and play area on the free play activities of 8-11 year old school children. Health Place 2008;14:386-93.

6 Ridgers ND, Salmon J, Parrish A-M, et al. Physical activity during school recess: a systematic review. Am J Prev Med 2012:43:320-8.

7 D'Haese S, Van Dyck D, De Bourdeaudhuij I, et al. Effectiveness and feasibility of lowering playground density during recess to promote physical activity and decrease sedentary time at primary school. BMC Public Health 2013;13:1154.

8 Stanley RM, Boshoff K, Dollman J. Voices in the playground: a qualitative exploration of the barriers and facilitators of lunchtime play. J Sci Med Sport 2012;15:44-51.

9 Willenberg LJ, Ashbolt R, Holland D, et al. Increasing school playground physical activity: a mixed methods study combining environmental measures and children's perspectives. J Sci Med Sport 2010;13:210-6.

10 Gidlow CJ, Cochrane T, Davey R, et al. In-school and out-of-school physical activity in primary and secondary school children. J Sports Sci 2008;26:1411-9.

11 Frémeaux AE, Mallam KM, Metcalf BS, et al. The impact of schooltime activity on total physical activity: the activitystat hypothesis (EarlyBird 46). Int J Obes 2011;35:1277-83

12 Dale D, Corbin CB, Dale KS. Restricting opportunities to be active during school time: do children compensate by increasing physical activity levels after school? Res $Q$ Exerc Sport 2000;71:240-8.

13 Long MW, Sobol AM, Cradock AL, et al. School-day and overall physical activity among youth. Am J Prev Med 2013;45:150-7.

14 Fairclough SJ, Beighle A, Erwin $\mathrm{H}$, et al. School day segmented physical activity patterns of high and low active children. BMC Public Health 2012;12:406.

15 Goss P. Population growth: where will the pressure be most profound? Grattan Institute ed. Sydney: School Planning, Design and Construction Conference, 2016

16 NSW Department of Education. 2016 space management report. Sydney: NSW Government, 2016.

17 Learning through Landscapes. The basic need for school places challenges: guidance notes for governors, 2016.

18 Chancellor B. Primary school playgrounds: features and management in Victoria, Australia. Int J Play 2013;2:63-75.

19 NSW Department of Education. Educational facilities: standards and guidelines. Sydney: Department of Education, 2018. https://efsg.det. nsw.edu.au/

20 American Academy of Pediatrics, National Resource Center for Health and Safety in Child Care and Early Education, American Public Health Association. Caring for our children: National health and safety performance standards. Guidelines for early care and early education programs, 2011.

21 State of Victoria (Department of Education and Early Childhood Development). Guidelines for school Playgrounds: playground safety management. East Melbourne: Department of Education and Early Childhood Development, 2012.

22 Standards Australia. Playground equipment and surfacing development, installation, inspection, maintenance and operation (as 4685.0:2017. Standards Australia, 2017.

23 Hardy LL, Mihrashahi S, Drayton BA, et al. NSW schools physical activity and nutrition survey (spans) 2015: full report. Sydney: NSW Department of Health, 2016.

24 Australian Bureau of Statistics. Australian Statistical Geography Standard (ASGS)- Remoteness Structure. Canberra: Australian Bureau of Statistics, 2013.

25 Australian Bureau of Statistics. Australian standard classification of languages ASCL. 1267. 2nd edn. Canberra: Australian Bureau of Statistics, 2011.

26 World Health Organization. Anthro-Child growth Standards, 2007 Version 3.2.2. Geneva: World Health Organization, 2007.

27 Ashwell M, Hsieh SD. Six reasons why the waist-to-height ratio is a rapid and effective global indicator for health risks of obesity and how its use could simplify the International public health message on obesity. Int J Food Sci Nutr 2005;56:303-7.

28 Hardy LL, Booth ML, Okely AD. The reliability of the adolescent sedentary activity questionnaire (ASAQ). Prev Med 2007;45:71-4.

29 Australian Curriculum Assessment and Reporting Authority. Guide to understanding index of community Socio-educational advantage (ICSEA) values. Sydney: ACARA, 2015.

30 Prochaska JJ, Sallis JF, Long B. A physical activity screening measure for use with adolescents in primary care. Arch Pediatr Adolesc Med 2001;155:554-9.

31 NSW Department of Education and Training. Get skilled: get active. A K-6 resource to support the teaching of fundamental movement skills. Ryde,NSW Department of Education and Training, 2000.

32 Léger LA, Lambert J. A maximal multistage 20-m shuttle run test to predict VO2 max. Eur J Appl Physiol Occup Physiol 1982;49:1-12.

33 Fernandez-Santos JR, Ruiz JR, Cohen DD, et al. Reliability and validity of tests to assess lower-body muscular power in children. $J$ Strength Cond Res 2015;29:2277-85.

34 Meredith M, Welk G. Fitnessgram: test administration manual: the Cooper Institute for aerobics research. Champaign IL: x: Human Kinetics Publishers, 2005.

35 Castro-Piñero J, Ortega FB, Artero EG, et al. Assessing muscular strength in youth: usefulness of standing long jump as a general 
index of muscular fitness. $J$ Strength Cond Res 2010;24:1810-7.

36 Catley MJ, Tomkinson GR. Normative health-related fitness values for children: analysis of 85347 test results on 9-17-year-old Australians since 1985. Br J Sports Med 2013;47:98-108.

37 Pitney Bowes. GeoVision. Australia: Pitney Bowes, 2018.

38 PSMA Australia Limited. Psma CadLite (Polygon. AURIN Portal, 2017.

39 ESRI. ESRI ArcGIS. desktop version 10.5.1. Redlands, CA: Environmental Systems Research Institute, 2018.

40 Engelen L, Bundy AC, Naughton G, et al. Increasing physical activity in young primary school children--it's child's play: a cluster randomised controlled trial. Prev Med 2013;56:319-25.

41 Australian Bureau of Statistics. Regional population growth, Australia (report 3218.0), table 1 estimated resident population, statistical areas level 2. New South Wales,Canberra: Australian Bureau of Statistics,, 2016.

42 Giles-Corti B, Hooper B, Foster S, et al. Low density development: impacts on physical activity and associated health outcomes: evidence review. Docklands, Victoria: National Heart Foundation of Australia, 2014.

43 Harrell FEJ. Regression modeling strategies: with applications to linear models, logistic regression, and survival analysis. New York: Springer, 2001.

44 Shepherd BE, Rebeiro PF, Caribbean, Central and South America network for HIV epidemiology. Brief report: assessing and interpreting the association between continuous covariates and outcomes in observational studies of HIV using splines. J Acquir Immune Defic Syndr 2017;74:e60.

45 R: A language and environment for statistical computing. $R$ Foundation for Statistical Computing [program. Vienna, Austria: R Foundation for Statistical Computing, 2019.

46 Lumley T. Analysis of complex survey samples. J Stat Softw 2004:9:1-19.
47 Hardy LL, Reinten-Reynolds T, Espinel P, et al. Prevalence and correlates of low fundamental movement skill competency in children. Pediatrics 2012;130:e390-8.

48 Hardy LL, Ding D, Peralta LR, et al. Association Between Sitting, Screen Time, Fitness Domains, and Fundamental Motor Skills in Children Aged 5-16 Years: Cross-Sectional Population Study. J Phys Act Health 2018;15:933-40.

49 The Urban Developer. 7 vertical schools proving Australia's education system is on the way up. The Urban Developer, 2018.

50 McDonald NC. Children's mode choice for the school trip: the role of distance and school location in walking to school. Transportation 2007;35:23-35.

51 Steinbach R, Green J, Edwards P. Look who's walking: social and environmental correlates of children's walking in London. Health Place 2012;18:917-27.

52 Jacobsen PL, Racioppi F, Rutter H. Who owns the roads? how motorised traffic discourages walking and bicycling. Inj Prev 2009:15:369-73.

53 Lin B, Meyers J, Barnett G. Understanding the potential loss and inequities of green space distribution with urban densification. Urban For Urban Green 2015;14:952-8.

54 Blaschke P, Chapman R, Randal NP. Does population density affect access to and satisfaction with urban green and open spaces? A review for the resilient urban futures programme strand on compact and dispersed development Wellington:New Zealand centre for sustainable cities, 2017. http://sustainablecities.org.nz/wp-content/ uploads/Blaschke-Chapman-et-al-30may17-on-Density-and-UGOSfinal-delinked.pdf

55 Wickel EE, Eisenmann JC. Contribution of youth sport to total daily physical activity among 6- to 12-yr-old boys. Med Sci Sports Exerc 2007;39:1493-500.

56 Goss P. People pressure: planning changes in your school population. Education Matters Magazine, 2016.

57 Cole TJ, Lobstein T. Extended International (IOTF) body mass index cut-offs for thinness, overweight and obesity. Pediatr Obes 2012; 7:284-94. 